\title{
How we use rules to select actions: A review of evidence from cognitive neuroscience
}

\author{
SILVIA A. BUNGE \\ University of California, Davis, California
}

\begin{abstract}
Much of our behavior is guided by rules, or prescribed guides for action. In this review, I consider the current state of knowledge of how rules are learned, stored in the brain, and retrieved and used as the need arises. The focus is primarily on studies in humans, but the review is informed by relevant studies in nonhuman primates. Ventrolateral prefrontal cortex (VLPFC) has been implicated in rule learning, retrieval from long-term memory, and on-line maintenance during task preparation. Interactions between VLPFC and temporal cortex are required for rule retrieval in nonhuman primates, and brain imaging findings in humans suggest that rule knowledge is stored in the posterior middle temporal gyrus. Dorsolateral PFC appears to be more closely related to rule-based response selection than to rule retrieval. An important task for the future is to explain how PFC, basal ganglia, and temporal, parietal, and motor cortices interact to produce rule-guided behavior.
\end{abstract}

Meaningful stimuli that we encounter in our daily lives trigger the retrieval of associations - that is, links that we have previously made between these stimuli and other stimuli, potential responses, heuristics for responding, or rewards. These associations are often used to rapidly select an appropriate course of action for a given situation in which we find ourselves. As such, much of our behavior is guided by rules, or "prescribed guide[s] for conduct or action" (Merriam-Webster Dictionary, 1974). We rely on a variety of rules, including both simple stimulus-response (S-R) associations (e.g., a red light means that you should stop) and rules with response contingencies (e.g., a carpool sign means that you can use the lane if two or more people are in the car, but not otherwise). Rules are explicit constructs (M. A. Bunge, 2003), but they can be either explicitly learned, as in the case of arbitrary symbols such as road signs that are associated with specific meanings, or implicitly learned, as in the case of unspoken rules for social interaction.

To understand how we use rules to determine our actions, it is critical to learn more about how we select responses on the basis of associations in long-term memory. In the setting of a cognitive neuroscience laboratory, the most tractable way to investigate the interface between memory and action is to study the neural representation of simple rules of behavior. This review covers the current state of knowledge of the neural systems involved in various aspects of rule use: acquisition, long-

This manuscript is dedicated to the memory of Patricia S. GoldmanRakic (1937-2003). I thank members of my laboratory for their work on the projects described here: Eveline Crone, Sarah Donohue, Jesse Edelstein, and Carter Wendelken. I also thank my father, Mario Bunge, for helpful discussions on the nature of rules. Correspondence concerning this article should be addressed to S. A. Bunge, Center for Mind and Brain, University of California, 202 Cousteau Place, Suite 201, Davis, CA 95616 (e-mail: sbunge@ucdavis.edu). term storage, retrieval, maintenance, and implementation (i.e., selection of a response on the basis of task rules). Also discussed below is the ability to flexibly switch between task rules, which can be considered a component of rule implementation. The distinction between these aspects of rule use has been drawn somewhat (although not entirely) arbitrarily, and it is important to construct a theoretical model of rule-guided behavior that can be tested empirically. This review focuses primarily on studies in humans but is informed by relevant studies in nonhuman primates.

\section{Evidence From Neuropsychology and Electrophysiology}

Research on the neural substrates of rule representation has thus far focused primarily on lateral prefrontal cortex (LatPFC), a region that includes mid-dorsolateral PFC (DLPFC; Brodmann areas [BAs] 9, 46) and ventrolateral PFC (VLPFC; BA 44, 45, 47). LatPFC is thought to be responsible for the ability to keep a goal in mind with no external cues present, and to use that goal to guide behavior in spite of previous reinforcement to act otherwise (Diamond \& Goldman-Rakic, 1989). Several lines of evidence support this claim. First, on the basis of what we know about its functional connectivity, it is argued that LatPFC is the part of the brain in which perception interfaces with action planning (Fuster, 1997). Second, patients with damage to LatPFC have trouble implementing or flexibly switching between rules on a variety of laboratory tasks, most famously in the Wisconsin Card-Sorting Task (WCST; see, e.g., Milner, 1963). Deficits in rule implementation are often observed when a strongly prepotent response tendency must be overridden in favor of a recently learned rule, as in the Stroop task (Miller \& Cohen, 2001). Third, monkeys with lesions to VLPFC have difficulty learning and using 
both simple $\mathrm{S}-\mathrm{R}$ associations and more complex rules (Bussey, Wise, \& Murray, 2002; Hoshi, Shima, \& Tanji, 2000; Murray, Bussey, \& Wise, 2000; Passingham, Toni, $\&$ Rushworth, 2000). Fourth, as will be described briefly below, the pivotal electrophysiological studies carried out by Patricia Goldman-Rakic, Joaquín Fuster, and others focused a spotlight on LatPFC by investigating its role in working memory.

These pioneers of $\mathrm{PFC}$ exploration ${ }^{1}$ noted that a high proportion of neurons in LatPFC were engaged during performance of working memory tasks. Notably, a subset of neurons exhibited sustained responses when monkeys were required to keep information in mind over a few seconds before using it to make a response (for reviews, see Curtis \& D'Esposito, 2004; Fuster, 1997; GoldmanRakic, 1987). Goldman-Rakic and colleagues showed that these neurons' firing properties were selective to the specific memorized cue (Constantinidis, Franowicz, \& Goldman-Rakic, 2001; Funahashi, Bruce, \& GoldmanRakic, 1989). There is now electrophysiological evidence that PFC neurons can maintain either a retrospective code (maintenance of a cue stimulus) or a prospective code (planning an upcoming response) during the delay (Hoshi et al., 2000; Quintana \& Fuster, 1992; Rainer, Rao, \& Miller, 1999; Takeda \& Funahashi, 2002; for a review, see Funahashi \& Takeda, 2002; Fuster, 2000), and there is also fMRI evidence that these two types of codes are maintained in PFC in humans (D'Esposito, Ballard, Zarahn, \& Aguirre, 2000). LatPFC neurons exhibit sustained delay period activity that is sensitive to specific conjunctions between stimuli and responses (Asaad, Rainer, \& Miller, 1998) or to specific rules (Asaad, Rainer, \& Miller, 2000; Fuster, Bodner, \& Kroger, 2000; White \& Wise, 1999). These task rules can be maintained in an abstract form in LatPFC - that is, without regard for the modality of the stimulus cuing the rule (Wallis, Anderson, \& Miller, 2001). Thus, these more recent findings demonstrate quite convincingly that neurons in PFC can maintain a rule online until it is to be implemented.

These results implicate LatPFC in learning new rules, retrieving them from long-term memory, and using them to control behavior. However, LatPFC is unlikely to be the long-term repository of memories for rules. Neuropsychological observations suggest that LatPFC patients can sometimes tell the experimenter what the appropriate task rule is, even while being unable to implement it correctly (Shallice \& Burgess, 1991). Similar observations have been made in the developmental literature, suggesting that the growth of knowledge sometimes proceeds faster than the ability to control behavior (Zelazo, Frye, \& Rapus, 1996). Patients with compromised LatPFC function are in fact often described as being overly reliant on well learned rules, to the extent that they have difficulty overriding these rules in favor of weaker but more contextually appropriate rules (see, e.g., Braver \& Barch, 2002; Cohen \& Servan-Schreiber, 1992; Miller \& Cohen, 2001). The idea that LatPFC retrieves and implements rules of behavior from long-term stores in other brain regions is consistent with the long-term memory literature, which implicates LatPFC in strategic or controlled memory retrieval rather than in long-term mnemonic storage (Gabrieli, Poldrack, \& Desmond, 1998; Gershberg \& Shimamura, 1995; Sylvester \& Shimamura, 2002; Wagner, Pare-Blagoev, Clark, \& Poldrack, 2001). In summary, these findings suggest that rule storage and rule implementation may be neurally dissociable.

Although Wallis and Miller (2003) have found evidence of rule retrieval in LatPFC neurons, they have also shown that neurons in dorsal premotor cortex (PMd) distinguished between rules $135 \mathrm{msec}$ earlier, on average, than those in LatPFC. As the authors note, this finding could be the result of extensive training on these rules. It may be that for well practiced rules LatPFC receives an efference copy of the rule rather than assisting in retrieving it from long-term memory. This efference copy could be useful for establishing context, especially if it becomes necessary to override the rule in question (Wallis \& Miller, 2003). This account could explain why neuropsychological observations suggest that we don't depend on LatPFC to retrieve well learned rules, even though neuroimaging studies show that PFC is active during rule retrieval. We have now conducted an fMRI study in which subjects retrieve the meanings of well learned rules, in part to gauge the level of involvement of LatPFC (see the discussion of Donohue, Wendelken, Crone, \& Bunge, 2004, below).

\section{Contributions of Functional Brain Imaging to the Study of Rule Use}

Brain imaging techniques used in humans, in particular fMRI, are proving to be helpful in several ways with regard to uncovering the neural mechanisms underlying rule use. First, fMRI enables us to look at the time course of learning-related changes in brain activation. Second, this method can be used to distinguish between the neural substrates that are likely to underlie rule storage, retrieval, and implementation. Third, it is possible to teach humans new and even complex rules in a single session rather than over the course of many months of training, as is the case with nonhuman primates. Moreover, it is fairly easy to probe humans for their knowledge of rules that they had acquired in the remote past. Studies that have made use of these three advantages of fMRI in humans are discussed below. In the future, methods that can be used to examine functional connectivity between brain regions should contribute significantly to our understanding of the dynamic interplay needed to retrieve and use task rules as needed (Sakai \& Passingham, 2003). The remainder of this review will focus on recent brain imaging studies that can be brought to bear on the neural mechanisms of rule use.

\section{Rule Learning}

In many of the neuropsychological and brain imaging studies on rule learning, tasks that encourage implicit learning have been used, such as probabilistic classification 
tasks (Knowlton, Mangels, \& Squire, 1996; Knowlton, Squire, \& Gluck, 1994; Poldrack et al., 2001; Shohamy et al., 2004) and artificial grammar learning (Fletcher, Buchel, Josephs, Friston, \& Dolan, 1999; Lieberman, Chang, Chiao, Bookheimer, \& Knowlton, 2004; Opitz \& Friederici, 2003; Seger et al., 2000; Skosnik et al., 2002; Strange, Henson, Friston, \& Dolan, 2001). These studies implicate the dorsal striatum (caudate and putamen) in gradual, procedural rule learning involving trial-by-trial feedback, and the medial temporal lobes in declarative rule acquisition. Moreover, research in a variety of species implicates the basal ganglia and its dopaminergic inputs in the incremental acquisition of habits based on S-R associations (for a review, see Packard \& Knowlton, 2002).

Like the basal ganglia and medial temporal lobes, LatPFC has also been implicated in rule learning in both humans (Deiber et al., 1997; Petrides, 1997; Toni \& Passingham, 1999; Toni, Ramnani, Josephs, Ashburner, \& Passingham, 2001) and nonhuman primates (see Murray et al., 2000, for a review). VLPFC lesions in monkeys severely impair learning on visuomotor conditional (or visuomotor associative) tasks, which require subjects to use one of several arbitrary S-R mappings to respond to a visual stimulus (Murray et al., 2000; Passingham et al., 2000). These lesions impair both the ability to use associations learned preoperatively and the ability to rapidly learn new associations within a single session (Bussey, Wise, \& Murray, 2001). VLPFC receives its visual input from inferotemporal cortex (Pandya \& Yeterian, 1998), and therefore disruption of the white matter tracts connecting VLPFC and ipsilateral temporal cortex also leads to impaired visuomotor learning (Bussey et al., 2002; Parker \& Gaffan, 1998). In contrast to VLPFC damage, DLPFC damage causes few or no impairments on learning in this type of task in either humans or nonhuman primates (see Murray et al., 2000), with the exception of damage to posterior DLPFC in humans (BA 8; Petrides, 1997).

VLPFC's role in learning associations extends beyond visuomotor associations. VLPFC lesions or frontaltemporal disconnection in monkeys also lead to difficulties learning associations between visual stimuli (for a review, see Miyashita \& Hayashi, 2000). Furthermore, VLPFC damage in monkeys leads to difficulty learning a task in which the monkeys see two visual stimuli and must select the one that is associated with a reward (Parker \& Gaffan, 1998). Performance on this stimulus-reward association task does not hinge on intrahemispheric projections between temporal and prefrontal cortices (Eacott \& Gaffan, 1992), but rather may rely on frontal and temporal projections to the striatum (Parker \& Gaffan, 1998), a region heavily implicated in feedback processing in humans as well as other animals (Shohamy et al., 2004). Thus, VLPFC's role in learning stimulus-response and stimulus-stimulus associations is mediated in part by its connections with inferotemporal cortex. In contrast, its role in learning stimulus-reward associations may be mediated by VLPFC projections to the striatum. Finally, VLPFC lesions in monkeys lead to a deficit in learning a match-to-sample rule (Bussey et al., 2002). The latter finding suggests that VLPFC is important for learning complex rules as well as simple associations.

In accordance with this hypothesis, Ivan Toni and Richard Passingham have found that VLPFC activation increases as subjects learn visuomotor associations with feedback (Toni et al., 2001; see also Toni \& Passingham, 1999) but decreases as subjects perform well learned visuomotor associations (Toni et al., 2001). Using structural equation modeling in their fMRI data set, these authors have provided evidence for strengthened interactions between VLPFC and the striatum during learning (Toni, Rowe, Stephan, \& Passingham, 2002). Thus, VLPFC interactions with temporal cortex and/or the striatum are involved in the acquisition of associations between stimuli, responses, and feedback relating to these responses.

\section{Long-Term Rule Storage}

The question of where rule representations are stored in the brain has received little attention in the literature up to now. The lateral temporal lobes are a likely candidate for rule storage, given that they have been implicated in the long-term storage of both semantic and nonsemantic associations (Bussey et al., 2002; Martin \& Chao, 2001; Messinger, Squire, Zola, \& Albright, 2001; Thompson-Schill, 2003). The parietal lobes are an equally likely candidate, given their involvement in representing actions associated with the environment (Goodale \& Milner, 1992; Snyder, Batista, \& Andersen, 2000). Other structures involved in motor planning, including premotor cortex (Wallis and Miller, 2003), supplementary motor area (SMA), and pre-SMA (Picard \& Strick, 1996, 2001), also merit consideration. It is plausible that visual and semantic features of a rule are represented in temporal cortex, whereas actions associated with the rule are represented in parietal cortex and in premotor and supplementary motor regions (Bunge, Hazeltine, Scanlon, Rosen, $\&$ Gabrieli, 2002). A distributed network for rule representation would be consistent with the attribute specificity model of semantic knowledge, whereby different features (e.g., visual or functional) of a stimulus are stored in a distributed manner across brain regions involved in encoding these features (see Thompson-Schill, 2003, for a review).

We have conducted an fMRI study (Bunge, Kahn, Wallis, Miller, \& Wagner, 2003) whose goal was to build on the finding that individual neurons in macaque LatPFC can maintain abstract rules over a delay period (Wallis et al., 2001). Various findings from this fMRI study (the abstract rule study) will be discussed in several of the ensuing sections, and therefore the logic of this experiment is laid out here. In the study by Wallis et al., a sample stimulus was presented simultaneously with an instructional cue that indicated which rule to follow. After a delay during which both the sample stimulus and the 
rule were to be maintained, a probe stimulus was presented. At that time, the monkey had to make a response on the basis of whether or not the sample and probe matched and whether the currently relevant rule was the match rule or the nonmatch rule. In our fMRI study, we sought to determine the neural substrates of rule retrieval and abstract rule maintenance in humans. We used a task similar to that of Wallis et al., but which included a delay period during which subjects maintained only the rule, and also added a rule type.

In the abstract rule fMRI study, subjects were cued by verbal or nonverbal instructional cues to maintain a specific rule over a delay period (Figure 1A). The cues were arbitrary, and the subjects were explicitly instructed on their meaning prior to scanning. For compound rules, the subjects had to maintain a set of response contingencies (i.e., "press the left button if these conditions are met but the right button if those conditions are met"). For simple rules, they had only to maintain a specific response plan (e.g., "press the left button at the end of the trial"). After the delay, the subjects viewed a sample stimulus and a probe stimulus, to which they responded in a manner that depended on the rule (Bunge et al., 2003).

We reasoned that regions involved in either storing or retrieving rules should be active while the subjects viewed the instructional cues. Moreover, we reasoned that these regions should be modulated by rule complexity. As is shown in Figure 1B, several regions were more active for compound than for simple rules during the cue period, including left anterior VLPFC and left posterior middle temporal gyrus (postMTG). Neither of these regions maintained rule sensitivity during the delay period. On the basis of the broader memory literature, we surmised that left postMTG serves as a long-term repository for rule meanings, whereas anterior VLPFC works with temporal cortex to retrieve rule meanings (see the Rule Retrieval section below).

One intriguing aspect of the activation observed in postMTG is its proximity to a region that Alex Martin, Linda Chao, and others have characterized as storing knowledge about actions associated with manipulable objects (Beauchamp, Lee, Haxby, \& Martin, 2002; Chao, Haxby, \& Martin, 1999; Martin \& Chao, 2001; Tranel, Adolphs, Damasio, \& Damasio, 2001). Tyler et al. (2003) have extended Martin and Chao's findings by showing that postMTG is also activated when subjects view pictures of animals with which we have associated specific actions. This constellation of results raises the possibility that postMTG's role in storing action knowledge is a general one. This role may encompass both nonarbitrary associations between entities in the real world and specific actions, as well as completely arbitrary associations between symbols and associated rules for how to act.

We have now further explored the possibility that postMTG is involved in storing action knowledge associated with arbitrary symbols (Donohue et al., 2004). A central goal of the road sign study was to gauge the levels of involvement of postMTG and VLPFC during retrieval of

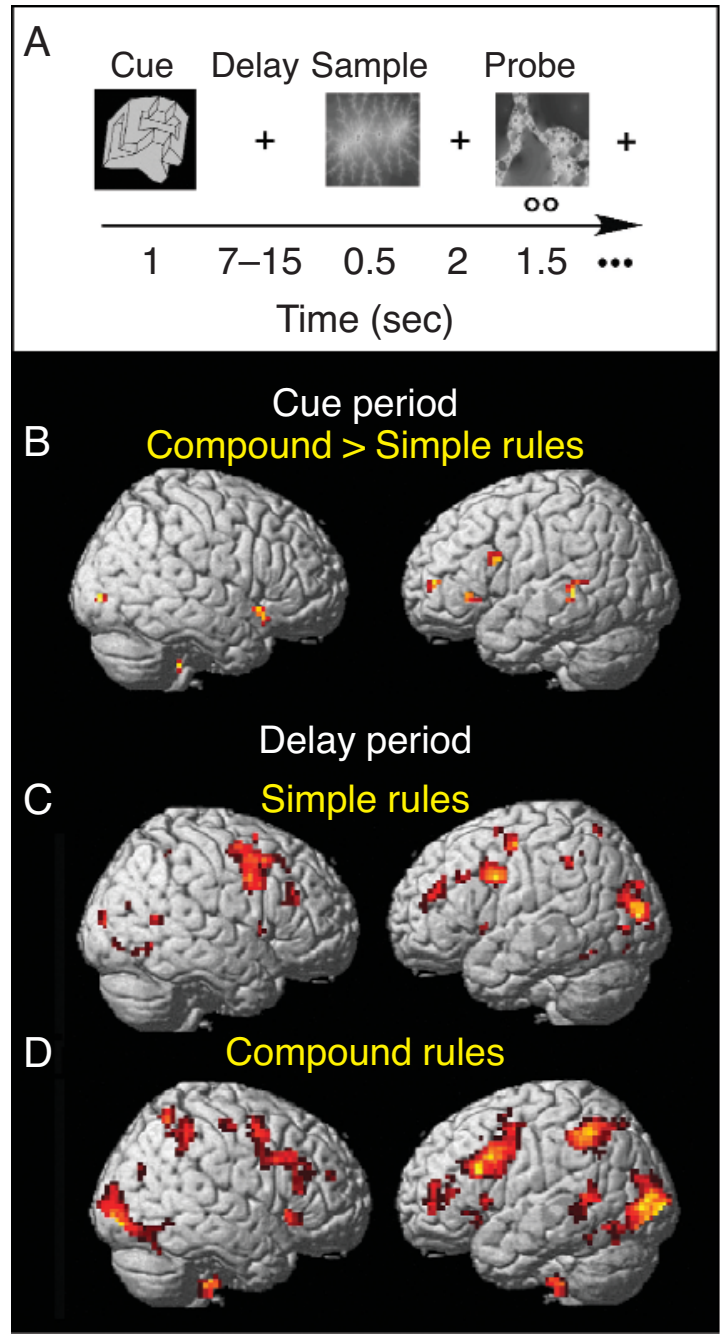

Figure 1. (A) The trial structure for the abstract rule study. On each trial, subjects saw an instructional cue - either a nonsense shape or a nonword-that they had previously learned to associate with a specific rule. Presentation of this cue was followed by a long and variable delay period, over which the subjects were expected to actively keep the relevant rule in mind. Then, a sample stimulus appeared on the screen, followed by a probe stimulus. On presentation of the probe stimulus, the subjects were to press either a left or a right button depending on the rule being followed and on whether the sample and probe stimuli matched. From "Neural Circuits Subserving the Retrieval and Maintenance of Abstract Rules," by S. A. Bunge, I. Kahn, J. D. Wallis, E. K. Miller, and A. D. Wagner, 2003, Journal of Neurophysiology, 90, p. 3420 . Copyright 2003 by the Americal Physiological Society. Reprinted with permission. (B) The regions in left PFC (anterior and posterior VLPFC and FPC) and postMTG modulated by rule complexity (compound $>$ simple rules) during presentation of the instructional cue (Bunge et al., 2003). Group-averaged data for 14 adults are rendered on a canonical brain. ( $p<.005$ uncorrected, masked at $p<.005$ to include only regions that were active relative to fixation during cue presentation). (C) Delay period activity associated with maintenance of a specific response plan (simple rules). (D) a set of response contingencies (compound rules). See Bunge et al. (2003) for a direct comparison between regions engaged more strongly by maintenance of compound versus maintenance of simple rules. 
well learned rules that had been encoded in the remote past. Subjects viewed images of road signs and were asked to think about the meaning of each sign. One third of the road signs that the subjects viewed in the scanner were common U.S. road signs (old), and one third were foreign signs that were shown prior to scanning but for which the meaning was not given. ${ }^{2}$ An additional third of the stimuli were foreign signs whose meanings the subjects had learned immediately prior to scanning (new trained). There were no response requirements during scanning, in order to better assess the level of involvement of PFC in retrieving the meanings of well learned rules. After scanning, the subjects were asked for the meaning of each sign, and we sorted the fMRI data according to their responses. As we expected, the subjects knew the meanings of the majority of the old signs $(89 \%)$, but very few of the meanings of the new-untrained signs (only 16\%). Thus, we had a sufficient number of trials to examine the effects of knowledge on brain activation (correctly retrieved vs. incorrectly retrieved sign meanings).

If postMTG is involved in storing representations of rule meaning, we reasoned, this region should be more active when subjects know the meaning of the sign they are viewing than when they do not. In keeping with our predictions, left postMTG was the region most strongly modulated by knowledge of rule meanings (Figure 2A). A comparison of activation foci confirmed that the MTG activations observed in both of our studies of rule representation (Donohue et al., 2004) overlapped with the foci observed in studies of action knowledge by Chao, Martin, and others (Figure 2B). However, the bulk of the rule activations were anterior to the bulk of the tool action foci. We are currently conducting a follow-up study involving both tools and abstract rules to conclusively determine the extent of overlap between their representations in temporal cortex.

The present results implicate regions in postMTG in the storage of knowledge about the actions or sets of pos- sible actions that have come to be associated with specific visual stimuli. Moreover, these results extend prior findings by showing that these associations can be either nonarbitrary, as in the case of knowledge about the way to use a hammer or the way a kangaroo hops, or arbitrary, as in the case of novel symbolic cues whose meaning we are explicitly taught (Donohue et al., 2004). Furthermore, the road sign study shows that postMTG responds to symbolic cues with associations that are quite abstract (e.g., "merge" or "one-way road ahead"), rather than merely relating to specific motoric responses.

\section{Rule Retrieval}

The neural correlates of rule retrieval have been examined in several event-related fMRI studies (Brass et al., 2003; Brass \& von Cramon, 2002, 2004; Bunge et al., 2003; Crone, Wendelken, Donohue, Honomichl, $\&$ Bunge, 2004). Typically in these studies, subjects have been trained on a set of cue-rule associations outside the scanner and brain activity has been measured while subjects hold the relevant rule in mind. At the end of each trial, subjects must use the relevant rule to make a decision regarding a stimulus or set of stimuli. To identify regions whose activation is related to rule retrieval, in these studies an attempt has been made to isolate fMRI activation associated with presentation of the instructional cue, and rule retrieval demands have been varied in several ways. One approach is to manipulate rule complexity, as was discussed earlier (Bunge et al., 2003). Other approaches are to examine learning-related changes in activation across trials (Toni, Krams, Turner, \& Passingham, 1998; Toni \& Passingham, 1999) and to compare the retrieval of well learned rules with that of less well learned rules (Donohue et al., 2004). Yet another approach is to compare rules with bivalent versus univalent targets - that is, distinct rules that operate on a shared set of target stimuli versus rules that operate on unique target stimuli (Brass et al., 2003; Crone et al., 2004). Fi-
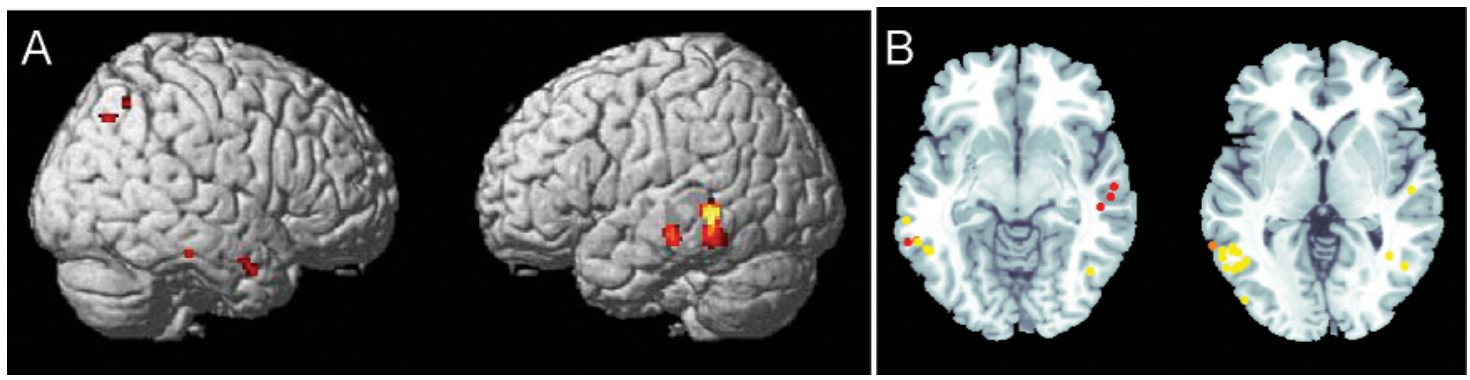

Figure 2. (A) Brain regions that were modulated by rule knowledge during passive viewing of road signs (14 adults; $p<.001$ uncorrected). PostMTG was more active for signs of which subjects knew the meanings than for signs whose meanings they did not know, on the basis of a postscan test. (B) Foci of activation from a meta-analysis of MTG activations are plotted on a canonical brain. Activations in postMTG from our rule studies are near those from studies of action knowledge. Orange foci are from Bunge, Kahn, Wallis, Miller, and Wagner, 2003; red foci are from Donohue, Wendelken, Crone, and Bunge, 2004; and yellow foci are from studies on action knowledge (Beauchamp, Lee, Haxby, \& Martin, 2003; Chao, Haxby, \& Martin, 1999; Choi et al., 2001; Damasio et al., 2001; Damasio, Tranel, Grabowski, Adolphs, \& Damasio, 2004; Devlin et al., 2002; Emmorey et al., 2004; Grossman et al., 2002; Kellenbach, Brett, \& Patterson, 2003; Kounios et al., 2003; Noppeney \& Price, 2003; Perani et al., 1995; Tyler et al., 2003). 
nally, another way to vary rule retrieval demands is to manipulate the number of times the same rule was retrieved on a given trial (Brass \& von Cramon, 2004).

The fMRI studies mentioned above have consistently implicated VLPFC in rule retrieval. In our abstract rule study, we found that left posterior and anterior VLPFC were modulated by rule complexity during presentation of the instructional cue (see Figure 1B). This rule sensitivity was maintained over the delay period in posterior VLPFC together with left parietal cortex, but not in anterior VLPFC, suggesting that the anterior portion is involved in retrieval but not in maintenance. Prior research focusing on left VLPFC has implicated anterior VLPFC (BA 45, 47, and anterior ventral BA 44) in semantic processing and in the controlled retrieval of semantic associations, ${ }^{3}$ whereas the more posterior region (BA 44/6) has been implicated in phonological processing and maintenance in verbal working memory (see, e.g., Poldrack et al., 1999; Wagner et al., 2001). Extending these findings, we suggested that left anterior VLPFC was involved in retrieving rule meanings from long-term stores in middle temporal cortex, and that left posterior VLPFC was involved in retrieving and actively maintaining phonological representations of the rule contingencies (Bunge et al., 2003).

In another fMRI study (the valence study), Eveline Crone and I manipulated rule retrieval and maintenance demands in a way that did not involve comparing rules of differing complexities (Crone et al., 2004). We taught
20 adult subjects three compound rules (i.e., rules that had a set of response contingencies associated with them) but varied whether or not the rules involved overlapping target stimuli (Figure 3A). In the case of the univalent rules, the subjects could perform the task simply by recalling a single $\mathrm{S}-\mathrm{R}$ association (e.g., press the left button in response to a flower). In contrast, for the bivalent rules, the subjects needed to remember the context in which a target stimulus appeared (e.g., the house target appeared after the circle cue) to determine the appropriate response (e.g., press the left button in response to a house). Thus, we would argue, the demands placed on rule retrieval and maintenance should be greater for bivalent than for univalent rules. We also expect greater response competition on bivalent than on univalent trials, because subjects must select between two alternative responses that have been associated with the same target stimulus. One goal of this study was to develop a relatively brief task that could be used easily to examine the development of rule use in children. As such, we used a short delay $(0.5 \mathrm{sec})$ between the cue and target stimuli that did not allow for separation of activation related to rule retrieval, maintenance, or implementation. One of our central predictions was that VLPFC would be more active while the subjects used bivalent rules than while they used univalent rules.

As was expected, whole-brain contrast of trials with bivalent versus univalent targets revealed activation in left posterior and anterior VLPFC (Figure 3B), in con-

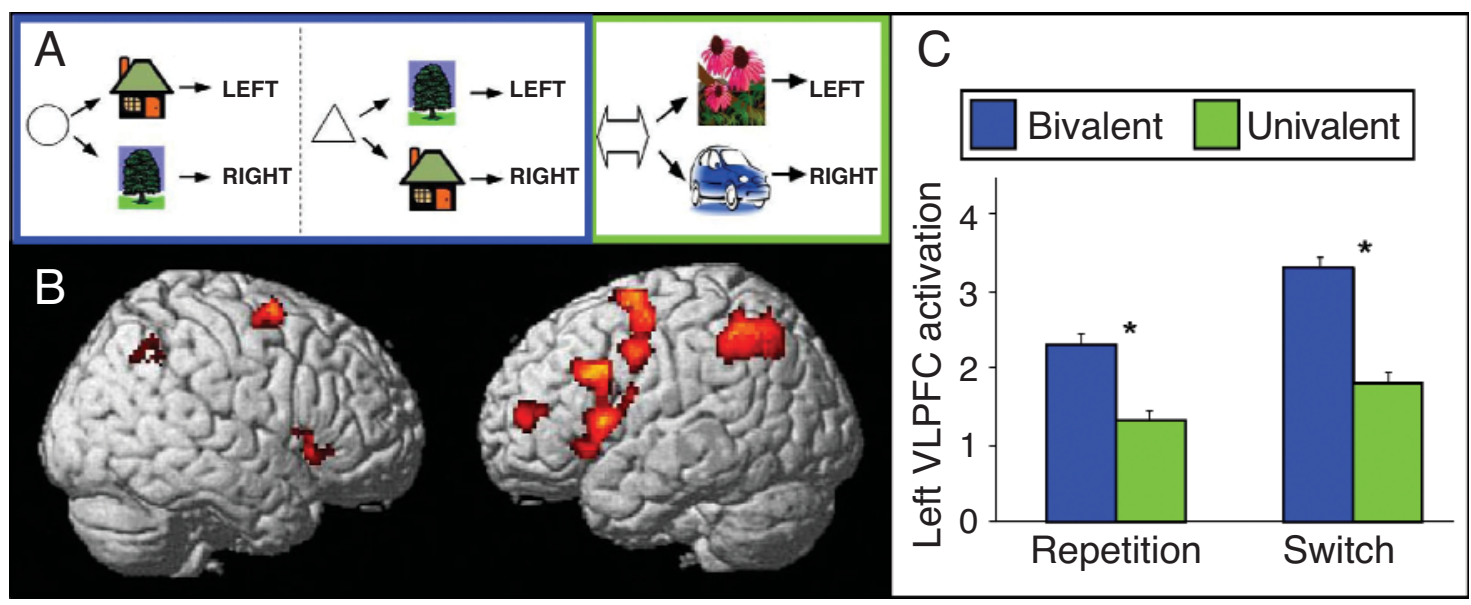

Figure 3. (A) The task used by Crone, Wendelken, Donohue, Honomichl, and Bunge (2004). When the cue was a circle, subjects were instructed to press a left button in response to a house but a right button in response to a tree. When the cue was a triangle, these response contingencies were reversed. In contrast, when the cue was a double arrow, the subjects were instructed to press a left button in response to a flower and a right button in response to a car. Thus, the circle and triangle cues were associated with bivalent targets, whereas the arrow cue was associated with univalent targets. (B) Regions exhibiting an effect of rule type (bivalent $>$ univalent; 20 adults; $p<.001$ uncorrected). Regions that were more active when the subjects had to use rules with overlapping targets relative to unique targets included left anterior and posterior VLPFC and FPC, as well as motor-related structures and parietal cortex. (C) A region-of-interest analysis in left anterior VLPFC reveals that this region was sensitive to rule type (bivalent $>$ univalent) for both rule repetition and rule switch trials, in consistency with a role in rule retrieval rather than with a role in overriding response competition. 
sistency with the rule complexity manipulation in our abstract rule study (Bunge et al., 2003). Additional activations in this contrast included posterior parietal and premotor cortices, regions expected to be involved in selecting the appropriate response under conditions of response competition (Bunge, Hazeltine, et al., 2002). Notably absent - even at a liberal significance threshold $(p<.05$ uncorrected) - was activation in postMTG or in any other region in lateral temporal cortex. This finding supports the claim made earlier that middle temporal cortex is involved in storing semantic associations for visual cues but not in activating the appropriate response representations. To address the concern that bivalent rules are likely to be associated with greater response competition than univalent rules, we have focused our comparison of bivalent and univalent rules on rule repetition trials (e.g., a circle cue trial following another circle cue trial), on which response competition should be minimal. On these rule repetition trials as well as on rule switch trials, left anterior VLPFC was engaged more strongly by bivalent than by univalent rules (Figure 3C). This finding supports the involvement of left anterior VLPFC in rule retrieval, and is consistent with other results in showing that this region is not sensitive to response competition per se (Nelson, Reuter-Lorenz, Sylvester, Jonides, \& Smith, 2003).

In an elegant series of studies, Marcel Brass, Yves von Cramon, and colleagues have proposed that a region in posterior VLPFC in or near the region discussed above is important for implementing task-set - that is, for using instructional cues to select relevant $\mathrm{S}-\mathrm{R}$ mappings (Brass et al., 2003; Brass \& von Cramon, 2002; Derrfuss, Brass, $\&$ von Cramon, 2004). They have termed this region the inferior frontal junction (IFJ) because it is at the anatomical junction between the inferior frontal sulcus and the precentral sulcus. The IFJ borders on several cytoarchitectonic areas: prefrontal area $8 \mathrm{Av}$, premotor area 6 , and premotor/prefrontal transition cortex BA 44 (Brass \& von Cramon, 2004). In these studies, the target stimulus on each trial is a number and subjects must either judge it as odd/even or as greater/smaller than 30, depending on the shape of the frame around the stimulus (Figure 4A).

Brass and colleagues have provided several compelling data points in favor of the hypothesis that left IFJ is involved in task preparation. First, this region is active when an instructional cue (a diamond or square frame) appears on the screen, regardless of whether this cue is followed by a target (i.e., the digit). Second, IFJ (along with left anterior VLPFC, pre-SMA, and dorsal premotor cortex) exhibits delayed activation if the cue stimulus appears together with the target rather than $1.2 \mathrm{sec}$ before it. Third, left IFJ (and pre-SMA) activation was delayed on trials associated with the slowest responses. The cue stimulus was always present during target presentation, so the subjects could wait until the target appeared before selecting a response. Therefore, it is likely that the slowest responses were ones in which the subjects failed to prepare the relevant $\mathrm{S}-\mathrm{R}$ mappings before the

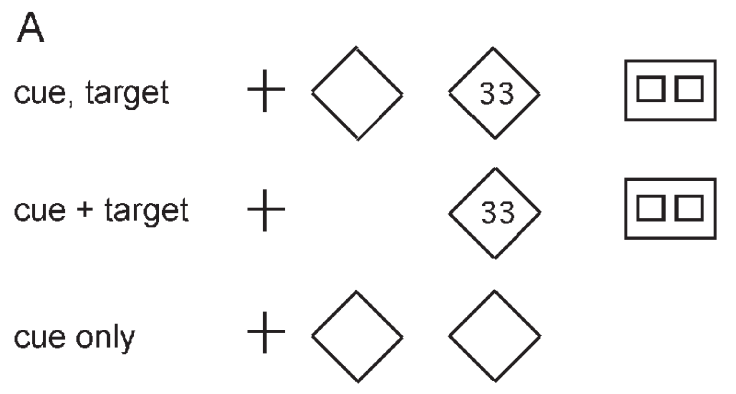

Time

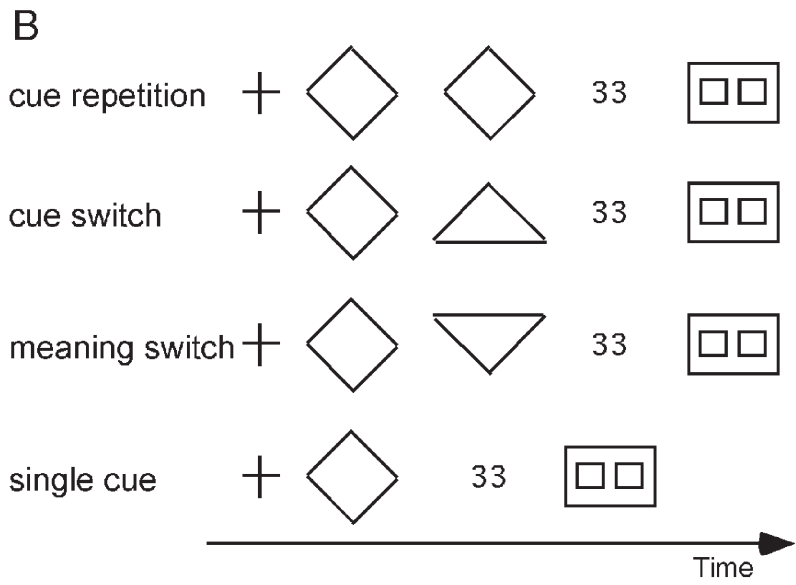

Figure 4. The task designs used by (A) Brass and von Cramon (2002) and (B) Brass and von Cramon (2004). (A) Subjects had to perform one of two tasks (decide whether the digit is odd or even, or decide whether it is greater or smaller than 30), depending on an instructional cue (a diamond frame or a square frame). On cue, target trials, the cue appeared prior to the digit, allowing the subjects to retrieve the relevant task rule ahead of time. On cue + target trials, the cue appeared concurrently with the digit. On cue-only trials, the subjects retrieved the relevant rule but were not asked to implement it. This design allows for the identification of brain regions involved in task preparation. (B) In this design, the initial cue is occasionally replaced with a new cue before the digit appears. The second cue refers either to the same rule as the first cue (cue switch trial) or to a different rule (meaning switch trial). This design enables the identification of brain regions involved in retrieving relevant $S-R$ associations. For more details about the task parameters, see Brass and von Cramon (2002, 2004).

target appeared. Critically, this delay was not observed in motor cortex, which suggests that the increased response times were not due specifically to slower motor execution. These findings in fact implicate both IFJ and pre-SMA in task preparation, although - as is discussed belowthe evidence is more compelling for IFJ.

To determine whether the IFJ effect was related to task preparation rather than cue processing, Brass and von Cramon (2004) conducted a study in which an initial cue stimulus was sometimes replaced with a new cue (Figure 4B). This cue could be associated with the same rule as the initial cue (referred to as a cue switch) or with a different rule (meaning switch-i.e., rule switch). The authors reasoned that if IFJ is specifically involved in 
preparing the relevant S-R mappings, it should be preferentially engaged by rule switch trials relative to both cue switch and cue repetition trials. Indeed, this pattern of results was observed in left IFJ. In contrast to IFJ, pre-SMA was sensitive to cue switches regardless of whether these constituted rule switches. This finding suggests that this region is not specifically involved in preparation to use the currently relevant response representations, but may instead play a more general role in task preparation (Brass \& von Cramon, 2004).

Together with our findings, these results suggest that left IFJ is not involved in retrieving cue-rule associations but, rather, in retrieving and maintaining the necessary response contingencies associated with the rule. The region to which we have ascribed the function of rule retrieval - left anterior VLPFC - is observed in several but not all of the expected contrasts in the studies by Brass and colleagues. One tentative explanation for this is that the demands on long-term memory rule retrieval were low in these studies. The subjects received a lot of practice and learned a total of only two or four cue-rule associations (M. Brass, personal communication, July 2004). These results suggest that left anterior VLPFC is not critical for retrieving well learned rules that have recently been retrieved, which would be consistent with the argument that left anterior VLPFC is important for the controlled, rather than automatic, retrieval of semantic associations.

As was noted earlier, neuropsychological studies suggest that LatPFC is not required for retrieval or implementation of well learned rules. We sought to gauge whether LatPFC would, nonetheless, be active while subjects in the road sign study viewed signs whose associated actions were well learned (Donohue et al., 2004). Right anterior VLPFC showed a pattern consistent with controlled rule retrieval - that is, greater activation for correctly retrieved new-trained than old or incorrectly retrieved signs. Because right VLPFC has been implicated previously in visual associative memory retrieval (Bunge, Burrows, \& Wagner, 2004), we hypothesized that this region is involved in retrieving nonverbal associations between visual cues and actions. In contrast to right VLPFC, we found that left anterior and posterior VLPFC were strongly engaged whenever the subjects viewed signs, in a manner that did not discriminate according to whether or not they knew the signs' meanings or whether the signs were well learned. Thus, these results suggest that under unconstrained viewing conditions in which subjects were encouraged to interpret the meaning of each sign, left anterior VLPFC was engaged in an effort to semantically elaborate on the signs' meanings. We are currently conducting a follow-up road sign study in which the retrieval requirements are more highly constrained, to test the hypothesis that left anterior VLPFC would be differentially engaged when the subject is selecting between competing sign meanings (see ThompsonSchill, D'Esposito, Aguirre, \& Farah, 1997; ThompsonSchill, D'Esposito, \& Kan, 1999). In summary, these fMRI results are consistent with the neuropsychological evidence in showing that involvement of LatPFC, at least in the right hemisphere, is greater for newly learned than for well learned rules.

\section{Rule Maintenance}

fMRI studies of active rule maintenance in humans consistently show that PFC is involved in maintaining rules on line. However, the particular subregions that are implicated vary from study to study. As will be argued below, the type of rule that is being maintained appears to be a critical factor in determining which PFC subregion is involved. Another important factor may be whether the rule is being actively rehearsed in working memory or whether it is activated at the start of the trial and "refreshed" (Johnson, Raye, Mitchell, Greene, \& Anderson, 2003) when the target stimulus appears. Todd Braver has made the distinction between proactive control (i.e., active, anticipatory goal maintenance) and reactive control (i.e., target-driven reactivation of the goal; see Braver, Reynolds, \& Donaldson, 2003); this distinction will need to be explicitly explored in future studies of rule representation. In the studies reviewed below, the assumption is that rules are maintained online for the duration of the delay period between an instructional cue and a target stimulus, and thus focus on brain regions exhibiting sustained responses during this delay period. The first study to explicitly examine task preparation with event-related fMRI is likely to have been one conducted by Ivan Toni, Richard Passingham, and colleagues (Toni, Schluter, Josephs, Friston, \& Passingham, 1999). In this study, subjects viewed cue stimuli that had previously been associated with specific buttonpresses and prepared to respond accordingly as soon as they heard a tone. Toni et al. (1999) used a new method for dissociating activity related to cue processing, delay period activity, and motor responding, through the use of a variable delay period. Preparatory activity during the delay period was associated with sustained activity in PMd and posterior parietal cortex but not in VLPFC (this region exhibited only cuerelated and movement-related activation), in consistency with the fact that the subjects did not need to maintain a rule, but rather a specific motor plan, in mind. The simple rule condition in our abstract rule study (Bunge et al., 2003), like the condition in the task used by Toni et al. (1999), required subjects to maintain a specific motor plan over a delay period (although in our study subjects had to postpone their responses until after the sample and probe stimuli had been presented). In consistency with the results of Toni et al. (1999), we observed sustained delay period activation for both simple and compound rules in dorsal premotor cortex as well as in pre-SMA, but not in VLPFC (Figures 1C, 1D).

Preliminary data from Melvyn Goodale and colleagues (Pratesi et al., 2004) further shows that pre-SMA and left inferior parietal lobule were more active when subjects maintained two S-R mappings (e.g., press A in response to a face but press $\mathrm{B}$ in response to a house, or press $\mathrm{A}$ in response to a face, but don't press in response to a 
house) than when they simply maintained a single response plan (press A in response to any stimulus). These results suggest that pre-SMA and parietal cortex maintain representations of possible responses online, at a level of abstraction high enough to include nonaction (Bunge, Hazeltine et al., 2002). In contrast, PMd, SMA, and anterior cingulate cortex were engaged more strongly when subjects prepared to select between two specific responses (press A vs. press B) relative to when they prepared to decide whether or not to make a specific response. In summary, there is convergent evidence that parietal, premotor, and medial prefrontal regions maintain S-R mappings online, at different stages of abstraction, while subjects prepare to respond.

In our abstract rule study, several regions were recruited for maintenance of compound rules that were minimally engaged during maintenance of simple motor plans: left posterior VLPFC - including the inferior frontal junction region described by Brass and von Cramon (2002) - and parietal cortex (Figure 1D; Bunge et al., 2003). Through region-of-interest analyses, we showed that posterior VLPFC and parietal cortex had activation profiles consistent with maintenance of abstract rulesthat is, delay period activation that was modulated by rule complexity (compound rules $>$ simple rules) but not by the type of cue (verbal vs. spatial) associated with the rule. The fact that the verbal working memory literature has implicated posterior VLPFC and parietal cortex in subvocal rehearsal (Smith \& Jonides, 1999; Wagner, Bunge, \& Badre, 2004) suggests that the active maintenance of response contingencies may be mediated in a manner similar to that of other verbalizable material. As in VLPFC, sustained activation was observed in DLPFC during the delay period. However, this delay period activity was not modulated by rule complexity. These data suggest that maintenance of specific rules was mediated by VLPFC rather than by DLPFC, although DLPFC may have been maintaining task goals at a more general level.

However, other fMRI research has implicated DLPFC in rule maintenance. Angus MacDonald, Cameron Carter, and colleagues have shown that in humans (as in monkeys) DLPFC can represent abstract rules over a delay (MacDonald, Cohen, Stenger, \& Carter, 2000). Subjects performed a Stroop task in which they received the instruction either to read the ensuing word aloud or to name the color in which the ink was printed. On colornaming trials, in which the subjects had to override their automatic tendency to read the word aloud, left DLPFC exhibited greater delay period activation than it exhibited on word-reading trials. In other words, DLPFC was engaged when the subjects prepared to override a prepotent response to the upcoming stimulus. In another study, Robert Hester, Hugh Garavan, and colleagues used a go/no-go paradigm in which subjects were sometimes, but not always, warned that they would have to withhold responding to an upcoming target (Hester et al., 2004). That study similarly showed that DLPFC (but not VLPFC) was more active when subjects are able to prepare to withhold a response than when they receive no advance warning. Thus, to summarize, some fMRI studies have implicated VLPFC but not DLPFC in rule maintenance, whereas others have implicated DLPFC but not VLPFC. How can these seemingly contradictory findings be reconciled? It may be that different PFC subregions are involved in rule maintenance, depending on rule type. According to this view, VLPFC - in particular left VLPFC - is implicated when subjects must maintain a set of response contingencies, whereas DLPFC is involved when subjects must prepare to override a strong response tendency. This hypothesis is being explicitly tested in our laboratory.

Evidence in support of the idea that different types of rules are represented in distinct PFC subregions comes from a study by Katsuyuki Sakai and Richard Passingham (2003). The task involved maintaining either verbal or spatial items in a forward or reverse order, and subjects were given an instructional cue 4-12 sec before the first to-beremembered item was displayed. The authors showed that left VLPFC was engaged when the subjects prepared to perform either of the two verbal working memory tasks (forward or backward maintenance), whereas the superior frontal sulcus and superior parietal cortex - regions implicated in spatial working memory-were engaged when the subjects prepared to perform either of the two spatial working memory tasks (Figure 5). In contrast, DLPFC was not engaged during maintenance of the task instructions, but it was engaged more strongly while the subjects reordered items than when they simply maintained them in the correct order. In summary, these studies (Bunge et al., 2003; Macdonald et al., 2000; Sakai \& Passingham, 2003) together suggest that (1) left VLPFC is involved in rule maintenance, particularly for situations in which we have a tendency to verbalize the task goals, and (2) DLPFC is engaged in rule maintenance when subjects maintain the goal of overriding a strong response tendency.

In Sakai and Passingham's (2003) study, right frontopolar cortex (FPC; BA 10) was engaged during rule maintenance, but in a manner that did not differ between verbal and spatial or forward and backward tasks. Intriguingly, however, the authors used functional correlational analyses to show that FPC tended to be relatively more strongly coupled with left VLPFC during preparation for the demanding backward verbal task, and with the superior frontal sulcus during preparation for the backward spatial task. This finding suggests that FPC may help to coordinate task performance by interacting with different PFC subregions depending on the situation (Sakai \& Passingham, 2003). We have also observed left FPC in our studies of rule representation (Bunge et al., 2003; Crone et al., 2004; see Figures 1B and 3B), and bilateral FPC has been implicated in rule learning (Strange et al., 2001). On the basis of the profile of rule sensitivity that we have observed in FPC, we have suggested that FPC elaborates on rule meanings that have been initially retrieved by anterior VLPFC (Bunge et al., 

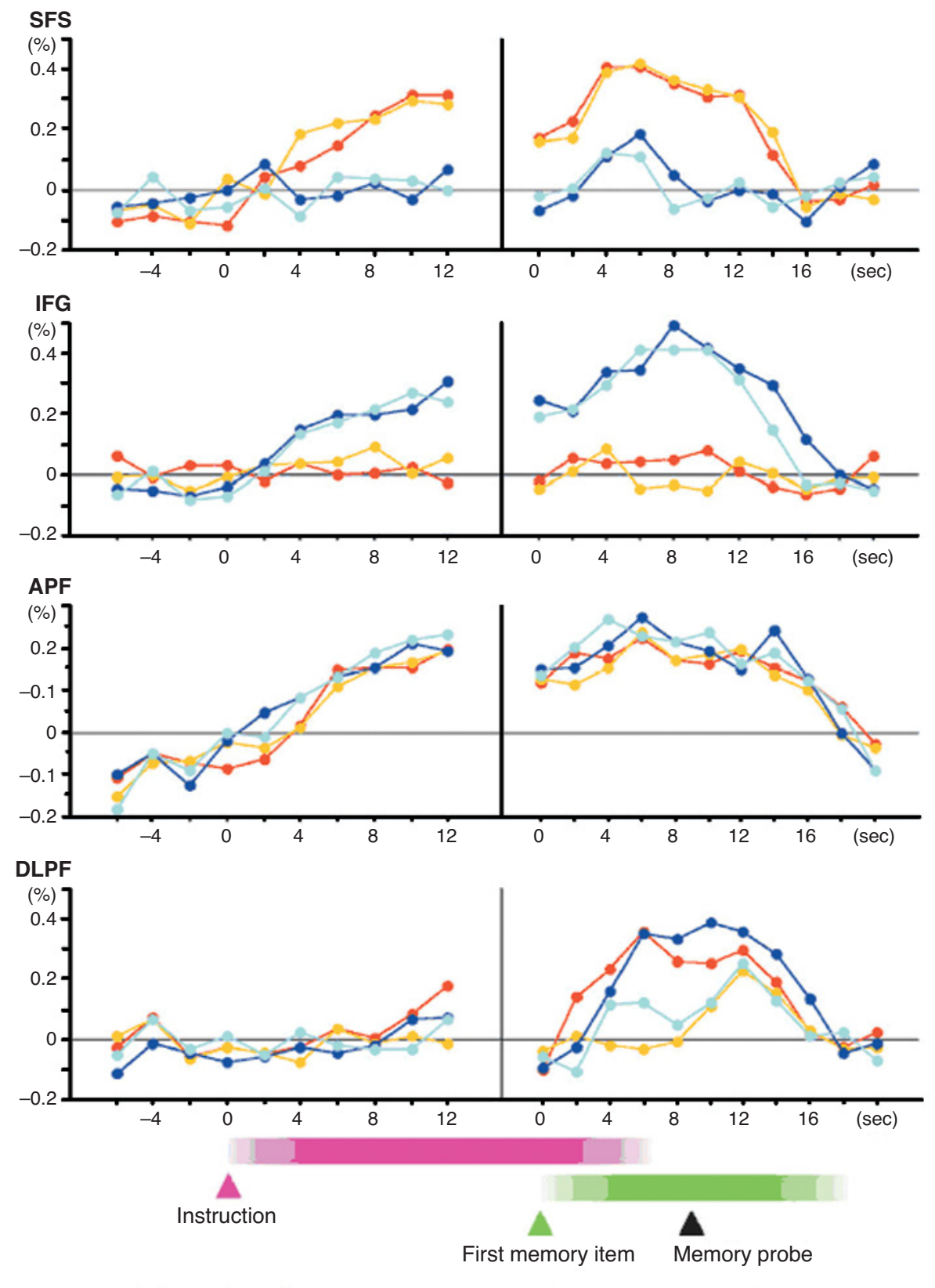

\section{Spatial-Forward

Figure 5. Time course of activation in PFC subregions from Sakai and Passingham (2003). Instruction-related activation is observed in the superior frontal sulcus (SFS) when subjects prepare to perform either of two spatial working memory tasks, and in left VLPFC (inferior frontal gyrus; IFG) when subjects prepare to perform either of two verbal working memory tasks. Anterior prefrontal cortex (APF), referred to in the text as FPC, exhibits instruction-related activation that does not differ according to task demands (although it is functionally correlated with SFS and VLPFC during performance of the spatial and verbal tasks, respectively.) Finally, DLPFC (labeled "DLPF" in the figure) does not show instruction-related activation, but instead is engaged more strongly when subjects must reorder the working memory items than when they can maintain them in the original order. For further details, see original publication. From "Prefrontal Interactions Reflect Future Task Operations," by K. Sakai and R. E. Passingham, 2003, Nature Neuroscience, 6, p. 79. Copyright 2003 by the Nature Publishing Group. Reprinted with permission. 
2003). A number of accounts of FPC contributions to task management have been proposed (Braver \& Bongiolatti, 2002; Bunge, Badre, \& Wagner, in press; Burgess, Quayle, \& Frith, 2001; Christoff \& Gabrieli, 2000; Koechlin, Basso, Pietrini, Panzer, \& Grafman, 1999; Ramnani \& Owen, 2004; Ranganath, Johnson, \& D'Esposito, 2000; Wendelken, Donohue, Crone, \& Bunge, 2004); however, the specifics of these accounts are beyond the scope of this review. In brief, the finding that FPC is active across a variety of task demands, and the fact that it is active even when subjects are maintaining relatively simple rules, speak to the general role of this region in task management.

\section{Flexible Rule Implementation}

Although the neural substrates of rule implementation are likely to be influenced by task demands, DLPFC may play a general role in selecting responses on the basis of representational memories (Goldman-Rakic, 1987), task rules, and goals. Indeed, Richard Passingham and James Rowe have argued that DLPFC, specifically mid-DLPFC, is important for selecting responses rather than for maintaining information in memory (Passingham \& Rowe, 2002). DLPFC is observed in brain imaging studies in which demands on response selection have been manipulated in various ways (Bunge, Hazeltine, et al., 2002; Hazeltine, Poldrack, \& Gabrieli, 2000; Rowe, Stephan, Friston, Frackowiak, \& Passingham, 2004; Schumacher \& D'Esposito, 2002; Schumacher, Elston, \& D'Esposito, 2003). DLPFC has been implicated in response selection regardless of whether the responses are made by the hands, mouth, eyes, or feet (see Rowe et al., 2004; for a neuropsychological study on oculomotor response selection, see Pierrot-Deseilligny et al., 2003). Moreover, several event-related fMRI studies have found that DLPFC is engaged at the point of response selection (Curtis \& D'Esposito, 2004; Rowe \& Passingham, 2001; Rowe, Toni, Josephs, Frackowiak, \& Passingham, 2000), although it should be noted that in other tasks DLPFC has been shown to be active earlier in the trial as well (Bunge et al., 2003; MacDonald et al., 2000; see also Funahashi et al., 1989).

In our abstract rule study, DLPFC was active during rule maintenance but did not display rule sensitivity until the end of the trial, when a response had to be selected. At this stage, right DLPFC was engaged more when the subjects used the nonmatch rule than when they used the match rule (unpublished result). Behaviorally, the subjects performed worse on the nonmatch rule than on the match rule, possibly because they had been instructed that the nonmatch rule was the reverse of the match rule. Thus, on nonmatch trials DLPFC may have been involved in overriding the tendency to respond to the match rule. However, this hypothesis remains to be tested explicitly. Another intriguing observation was that PFC activation on the rule trials appeared to progress from being primarily left lateralized during cue presentation to being bilateral during the delay period and primarily right lat- eralized during the sample/probe phase. This pattern tentatively suggests that - at least in this task - rule meaning is initially retrieved by left PFC, whereas rule-based response selection is accomplished primarily by right PFC. An event-related potentials study could be used to test this claim further. Such a finding would be consistent with the claim that right LatPFC (in particular VLPFC, but also DLPFC) plays an important role in response selection (Aron, Fletcher, Bullmore, Sahakian, \& Robbins, 2003; Aron, Robbins, \& Poldrack, 2004; Bunge, Dudukovic, Thomason, Vaidya, \& Gabrieli, 2002; Garavan, Ross, \& Stein, 1999; Konishi et al., 1999).

To effectively implement a set of task rules, it is often necessary to switch flexibly between rules as the need arises. This ability, referred to as task-switching, is discussed here in relation to rule use. PFC is thought to be involved in flexibly switching between tasks or rules, in part on the basis of the finding that patients with PFC damage tend to perseverate on previously relevant task rules in the WCST (Barcelo \& Knight, 2002; Stuss et al., 2000). In a study with several groups of PFC patients, medial PFC damage was associated with the greatest number of perseverative errors on the WCST, followed by LatPFC (Stuss et al., 2000). However, the WCST requires not just the ability to switch between rules, but also the ability to test hypotheses regarding the relevant rule in response to performance feedback. As a result, it is unclear precisely which component(s) of the WCST prefrontal patients are unable to perform. Transcranial magnetic stimulation experiments have demonstrated the importance of medial PFC (specifically, pre-SMA) and parietal cortex in task-switching (Rushworth, Ellison, \& Walsh, 2001; Rushworth, Hadland, Paus, \& Sipila, 2002). Neuroimaging studies have also implicated medial PFC and parietal cortex in task-switching, but some studies have implicated lateral PFC as well (Brass \& von Cramon, 2002; Bunge et al., 2003; DiGirolamo et al., 2001; Dove, Pollmann, Schubert, Wiggins, \& von Cramon, 2000; Dreher \& Berman, 2002; Sohn, Ursu, Anderson, Stenger, \& Carter, 2000; Sylvester et al., 2003). However, several studies have failed to show robust differences in lateral PFC activation between task-switch and task-repeat trials (Braver et al., 2003; Bunge et al., 2003) and instead indicate that this region is transiently activated at the onset of both task-switch and task-repeat trials (Braver et al., 2003; Dreher \& Berman, 2002).

These findings suggest that LatPFC, and in particular VLPFC, may be involved in retrieving and maintaining relevant task rules rather than task-switching per se (see also Keele \& Rafal, 2000). According to this perspective, activation (or performance decrements) observed in some experiments for task-switch relative to task-repeat trials could result from the need to access a less recently retrieved task rule, rather than be related specifically to the need to "shift mental gears" by overriding the tendency to perform the previously performed task. We are explicitly testing this hypothesis in our valence study (Crone et al., 2004). 


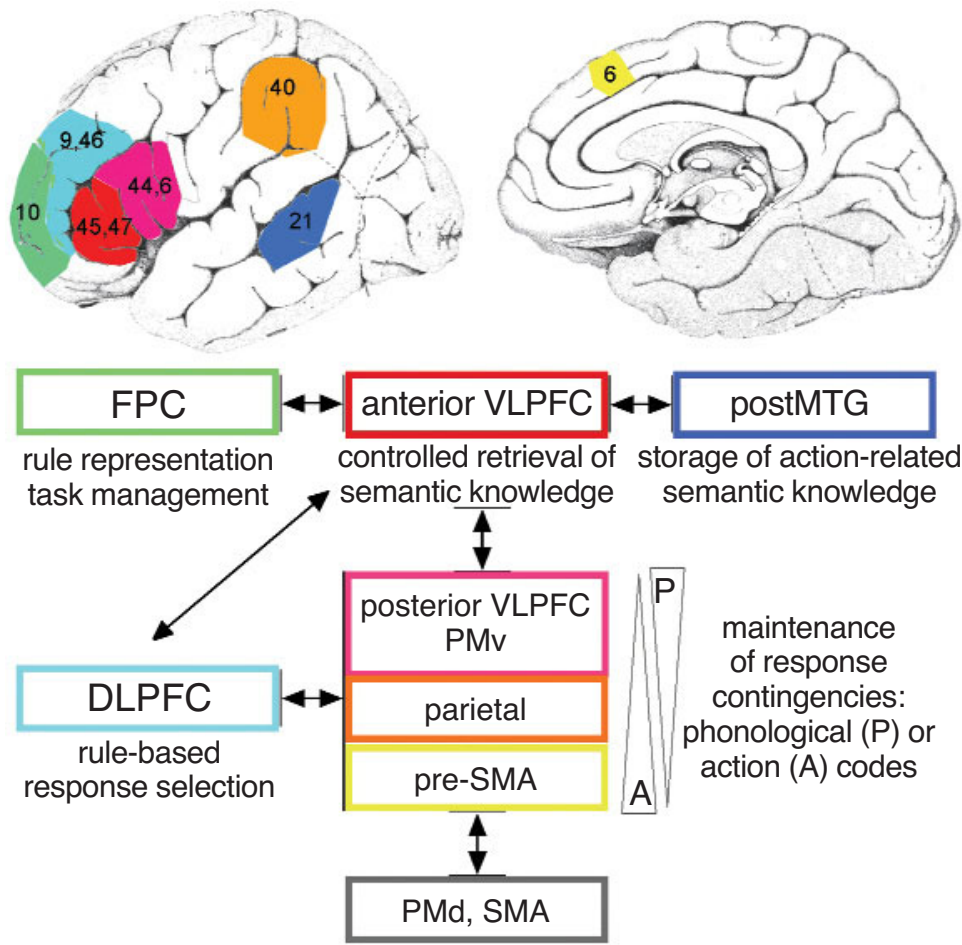

Figure 6. The brain regions that contribute to rule use are tentatively depicted in this schematic. According to this hypothetical framework, sets of possible actions associated with objects or visual symbols are learned through interactions between anterior VLPFC and postMTG. These associations are stored long term in postMTG and retrieved with the assistance of anterior VLPFC. Well learned rules can be retrieved automatically through bottom-up activation of postMTG, in the absence of interactions with VLPFC. FPC elaborates on rule meanings and/or participates in task management through its interactions with VLPFC. Once relevant rules have been retrieved, these are transformed into relevant response contingencies that can be maintained on line over a delay through interactions between posterior VLPFC, PMv, parietal cortex, and pre-SMA. Subjects can mentally rehearse response contingencies using a phonological code (P) and can also prepare to respond with one or more effectors, by maintaining relevant high-level (i.e., relatively abstract) action representations (A). Posterior VLPFC, PMv, parietal cortex, and pre-SMA are depicted as contributing to phonological and/or action code representation. These regions interact with PMd, SMA, and other motor structures to activate relevant motor representations so that subjects can take action. DLPFC receives information about the currently relevant rule from VLPFC and interacts with the regions that represent action/motor codes. These inputs from DLPFC enhance the activation of currently relevant response representations, ensuring that the correct response is selected when competing responses have been activated or when a strongly prepotent response must be overridden. Further investigations are needed to improve upon this framework. Black and white brain sketches were taken from Duvernoy (1991).

\section{Conclusion}

The findings discussed above are summarized in a schematic of the neural structures subserving rule use (Figure 6). This schematic is speculative and overly simplistic, which underscores the fact that more research is needed to better understand how we retrieve and use rules for behavior. Further investigation of the interactions between cortical and subcortical regions will be required to better understand how rules bridge the gap be- tween perception and action. I have focused here on the use of memorized rules that directly specify appropriate responses. In real life, however, there is often an indirect link between memory and response choice, and it will be important to further study how we make use of different kinds of memories to decide on a course of action (Bunge et al., in press).

To conclude, learning new rules is critical for the ability to behave meaningfully in the world, both in terms of 
planning our daily activities (Burgess, Veitch, de Lacy Costello, \& Shallice, 2000) and in terms of using knowledge about social rules in our interactions with others (Goel, Shuren, Sheesley, \& Grafman, 2004). Moreover, investigations of rule use are relevant to several lines of cognitive research, including routine action selection (Botvinick \& Plaut, 2004), cognitive control (Bunge et al., 2003; Miller, 2000), decision-making (for a review, see Ridderinkhof, van den Wildenberg, Segalowitz, \& Carter, 2004), and, arguably, problem-solving (Zelazo \& Müller, 2002). As such, the study of how rules are represented and used by the brain will enrich our understanding of human behavior.

\section{REFERENCES}

Aron, A. R., Fletcher, P. C., Bullmore, E. T., Sahakian, B. J., \& RobBINS, T. W. (2003). Stop-signal inhibition disrupted by damage to right inferior frontal gyrus in humans. Nature Neuroscience, 6, 115-116.

Aron, A. R., Robbins, T. W., \& Poldrack, R. A. (2004). Inhibition and the right inferior frontal cortex. Trends in Cognitive Sciences, $\mathbf{8}, 170$ 177.

Asaad, W. F., Rainer, G., \& Miller, E. K. (1998). Neural activity in the primate prefrontal cortex during associative learning. Neuron, $\mathbf{2 1}$, $1399-1407$

AsAaD, W. F., Rainer, G., \& Miller, E. K. (2000). Task-specific neural activity in the primate prefrontal cortex. Journal of Neurophysiology, 84, 451-459.

BARCELO, F., \& KNIGHT, R. T. (2002). Both random and perseverative errors underlie WCST deficits in prefrontal patients. Neuropsychologia, 40, 349-356.

BeAuchamp, M. S., Lee, K. E., Haxby, J. V., \& Martin, A. (2002). Parallel visual motion processing streams for manipulable objects and human movements. Neuron, 34, 149-159.

Beauchamp, M. S., Lee, K. E., HaX̄By, J. V., \& Martin, A. (2003). fMRI responses to video and point-light displays of moving humans and manipulable objects. Journal of Cognitive Neuroscience, $\mathbf{1 5}$, 991-1001.

Botvinick, M., \& Plaut, D. C. (2004). Doing without schema hierarchies: A recurrent connectionist approach to normal and impaired routine sequential action. Psychological Review, 111, 395-429.

Brass, M., Ruge, H., Meiran, N., Rubin, O., Koch, I. Zysset, S., Prinz, W., \& vON CRAMON, D. Y. (2003). When the same response has different meanings: Recoding the response meaning in the lateral prefrontal cortex. NeuroImage, 20, 1026-1031.

Brass, M., \& von CRAMON, D. Y. (2002). The role of the frontal cortex in task preparation. Cerebral Cortex, 12, 908-914.

Brass, M., \& VON CRAMON, D. Y. (2004). Decomposing components of task preparation with functional magnetic resonance imaging. Journal of Cognitive Neuroscience, 16, 609-620.

BRAVER, T. S., \& BARCH, D. M. (2002). A theory of cognitive control, aging cognition, and neuromodulation. Neuroscience \& Biobehavioral Reviews, 26, 809-817.

BRAVER, T. S., \& Bongiolatti, S. R. (2002). The role of frontopolar cortex in subgoal processing during working memory. NeuroImage, 15, 523-536.

BrAVER, T. S., Reynolds, J. R., \& Donaldson, D. I. (2003). Neural mechanisms of transient and sustained cognitive control during task switching. Neuron, 39, 713-726.

Bunge, M. A. (2003). Philosophical dictionary. Amherst, NY: Prometheus.

Bunge, S. A., BAdre, D., \& WAgner, A. D. (in press). Analogical reasoning and prefrontal cortex: Evidence for separable retrieval and integration mechanisms. Cerebral Cortex.

Bunge, S. A., Burrows, B., \& Wagner, A. D. (2004). Prefrontal and hippocampal contributions to visual associative retrieval. Brain \& Cognition, 56, 141-152.

Bunge, S. A., Dudukovic, N. M., Thomason, M. E., Vaidya, C. J., \&
Gabrieli, J. D. (2002). Immature frontal lobe contributions to cognitive control in children: Evidence from fMRI. Neuron, 33, 301-311. Bunge, S. A., Hazeltine, E., Scanlon, M. D., Rosen, A. C., \& Gabrieli, J. D. (2002). Dissociable contributions of prefrontal and parietal cortices to response selection. Neurolmage, 17, 1562-1571.

Bunge, S. A., Kahn, I., Wallis, J. D., Miller, E. K., \& Wagner, A. D. (2003). Neural circuits subserving the retrieval and maintenance of abstract rules. Journal of Neurophysiology, 90, 3419-3428.

Burgess, P. W., QuAYle, A., \& Frith, C. D. (2001). Brain regions involved in prospective memory as determined by positron emission tomography. Neuropsychologia, 39, 545-555.

Burgess, P. W., Veitch, E., De Lacy Costello, A., \& Shallice, T. (2000). The cognitive and neuroanatomical correlates of multitasking. Neuropsychologia, 38, 848-863.

BusSEY, T. J., Wise, S. P., \& MurRay, E. A. (2001). The role of ventral and orbital prefrontal cortex in conditional visuomotor learning and strategy use in rhesus monkeys (Macaca mulatta). Behavioral Neuroscience, 115, 971-982.

Bussey, T. J., WISE, S. P., \& Murray, E. A. (2002). Interaction of ventral and orbital prefrontal cortex with inferotemporal cortex in conditional visuomotor learning. Behavioral Neuroscience, 116, 703-715.

Chao, L. L., HAXвY, J. V., \& MARTIN, A. (1999). Attribute-based neural substrates in temporal cortex for perceiving and knowing about objects. Nature Neuroscience, 2, 913-919.

Chol, S. H., NA, D. L., KANG, E., LeE, K. M., Lee, S. W., \& NA, D. G. (2001). Functional magnetic resonance imaging during pantomiming tool-use gestures. Experimental Brain Research, 139, 311-317.

Christoff, K., \& Gabrieli, J. D. E. (2000). The frontopolar cortex and human cognition: Evidence for a rostrocaudal hierarchical organization within the human prefrontal cortex. Psychobiology, 28, 168-186.

Cohen, J., \& Servan-Schreiber, D. (1992). Context, cortex, and dopamine: A connectionist approach to behavior and biology in schizophrenia. Psychological Review, 99, 45-77.

Constantinidis, C., Franowicz, M. N., \& Goldman-Rakic, P. S. (2001). The sensory nature of mnemonic representation in the primate prefrontal cortex. Nature Neuroscience, 4, 311-316.

Crone, E. A., Wendelken, C., Donohue, S. E., Honomichl, R. D., \& Bunge, S. A. (2004). Contribution of prefrontal subregions to developmental changes in rule use (CD ROM, Program No. 253.10, Abstracts viewer/itinerary planner). Washington, DC: Society for Neuroscience.

Curtis, C. E., \& D’Esposito, M. (2004). Persistent activity in the prefrontal cortex during working memory. Trends in Cognitive Sciences, 7, 415-423.

Damasio, H., Grabowski, T. J., Tranel, D., Ponto, L. L., Hichwa, R. D., \& DAMASIO, A. R. (2001). Neural correlates of naming actions and of naming spatial relations. NeuroImage, 13, 1053-1064.

Damasio, H., Tranel, D., Grabowski, T., Adol PHS, R., \& Damasio, A. (2004). Neural systems behind word and concept retrieval. Cognition, 92, 179-229.

Deiber, M. P., Wise, S. P., Honda, M., Catalan, M. J., Grafman, J., \& HalletT, M. (1997). Frontal and parietal networks for conditional motor learning: A positron emission tomography study. Journal of Neurophysiology, 78, 977-991.

Derrfuss, J., Brass, M., \& von Cramon, D. Y. (2004). Cognitive control in the posterior frontolateral cortex: Evidence from common activations in task coordination, interference control, and working memory. NeuroImage, 23, 604-612.

D’Esposito, M., BallarD, D., Zarahn, E., \& Aguirre, G. K. (2000). The role of prefrontal cortex in sensory memory and motor preparation: An event-related fMRI study. NeuroImage, 11, 400-408.

Devlin, J. T., Russell, R. P., Davis, M. H., Price, C. J., Moss, H. E., FAdiLI, M. J., \& Tyler, L. K. (2002). Is there an anatomical basis for category-specificity? Semantic memory studies in PET and fMRI. Neuropsychologia, 40, 54-75.

DIAMOND, A., \& GOLDMAN-RAKIC, P. S. (1989). Comparison of human infants and rhesus monkeys on Piaget's AB task: Evidence for dependence on dorsolateral prefrontal cortex. Experimental Brain Research, 74, 24-40.

DiGirola $\bar{M}$, G. J., Kramer, A. F., Barad, V., Cepeda, N. J., Weissman, D. H., Milham, M. P., Wszalek, T. M., Cohen, N. J., Banich, 
M. T., WebB, A., Belopolsky, A. V., \& McAuley, E. (2001). General and task-specific frontal lobe recruitment in older adults during executive processes: A fMRI investigation of task-switching. NeuroReport, 12, 2065-2071.

Donohue, S. E., Wendelken, C., Crone, E. A., \& Bunge, S. A. (2004). Retrieving rules for behavior from long-term memory. Manuscript submitted for publication.

Dove, A., Pollmann, S., Schubert, T., Wiggins, C. J., \& von CraMON, D. Y. (2000). Prefrontal cortex activation in task switching: An event-related fMRI study. Cognitive Brain Research, 9, 103-109.

Dreher, J. C., \& Berman, K. F. (2002). Fractionating the neural substrate of cognitive control processes. Proceedings of the National Academy of Sciences, 99, 14595-14600.

Duvernoy, H. M. (1991). The human brain: Surface three-dimensional section anatomy and MRI. New York: Springer-Verlag.

EACOTT, M. J., \& GAFFAN, D. (1992). Inferotemporal-frontal disconnection: The uncinate fascicle and visual associative learning in monkeys. European Journal of Neuroscience, 4, 1320-1332.

Emmorey, K., Grabowski, T., McCullough, S., Damasio, H., Ponto, L., Hichwa, R., \& BeLlugi, U. (2004). Motor-iconicity of sign language does not alter the neural systems underlying tool and action naming. Brain \& Language, 89, 27-37.

Fletcher, P., Buchel, C., Josephs, O., Friston, K., \& Dolan, R. (1999). Learning-related neuronal responses in prefrontal cortex studied with functional neuroimaging. Cerebral Cortex, 9, 168-178.

Funahashi, S., Bruce, C. J., \& Goldman-Rakic, P. S. (1989). Mnemonic coding of visual space in the monkey's dorsolateral prefrontal cortex. Journal of Neurophysiology, 61, 331-349.

Funahashi, S., \& TAKEDA, K. (2002). Information processes in the primate prefrontal cortex in relation to working memory processes. Reviews in the Neurosciences, 13, 313-345.

Fuster, J. M. (1997). The prefrontal cortex: Anatomy, physiology, and neuropsychology of the frontal lobe. New York: Lippincott-Raven.

Fuster, J. M. (2000). Prefrontal neurons in networks of executive memory. Brain Research Bulletin, 52, 331-336.

Fuster, J. M., BODNER, M., \& KROGER, J. K. (2000). Cross-modal and cross-temporal association in neurons of frontal cortex. Nature, $\mathbf{4 0 5}$, 347-351.

Gabrieli, J. D., Poldrack, R. A., \& Desmond, J. E. (1998). The role of left prefrontal cortex in language and memory. Proceedings of the National Academy of Sciences, 95, 906-913.

Garavan, H., Ross, T. J., \& SteIN, E. A. (1999). Right hemispheric dominance of inhibitory control: An event-related functional MRI study. Proceedings of the National Academy of Sciences, 96, 83018306.

Gershberg, F. B., \& Shimamura, A. P. (1995). Impaired use of organizational strategies in free recall following frontal lobe damage. Neuropsychologia, 33, 1305-1333.

Goel, V., Shuren, J., Sheesley, L., \& Grafman, J. (2004). Asymmetrical involvement of frontal lobes in social reasoning. Brain, 127 783-790.

GOLDMAN-RAKIC, P. S. (1987). Circuitry of primate prefrontal cortex and regulation of behavior by representational memory. In J. M. Brookhart \&. V. B. Mountcastle (Series Eds.) \& F. Plum (Vol. Ed.), Handbook of physiology: Section 1. The nervous system: Vol. 5. Higher functions of the brain (pp. 373-417). Washington, DC: American Physiological Society.

Goodale, M. A., \& Milner, A. D. (1992). Separate visual pathways for perception and action. Trends in Neurosciences, 15, 20-25.

Grossman, M., Koenig, P., DeVita, C., Glosser, G., Alsop, D., Detre, J., \& GeE, J. (2002). The neural basis for category-specific knowledge: An fMRI study. NeuroImage, 15, 936-948.

Hazeltine, E., Poldrack, R., \& Gabrieli, J. D. (2000). Neural activation during response competition. Journal of Cognitive Neuroscience, 12, 118-129.

Hester, R. L., Murphy, K., Foxe, J. J., Foxe, D. M., Javitt, D. C., \& Garavan, H. (2004). Predicting success: Patterns of cortical activation and deactivation prior to response inhibition. Journal of Cognitive Neuroscience, 16, 776-785.

Hoshi, E., Shima, K., \& TANJI, J. (2000). Neuronal activity in the pri- mate prefrontal cortex in the process of motor selection based on two behavioral rules. Journal of Neurophysiology, 83, 2355-2373.

Johnson, M. K., RaYe, C. L., Mitchell, K. J., Greene, E. J., \& ANDERSON, A. W. (2003). fMRI evidence for an organization of prefrontal cortex by both type of process and type of information. Cerebral Cortex, 13, 265-273.

Jonides, J., Smith, E. E., Marshuetz, C., Koeppe, R. A., \& ReuterLORENZ, P. A. (1998). Inhibition in verbal working memory revealed by brain activation. Proceedings of the National Academy of Sciences, 95, 8410-8413.

KEELE, S. W., \& RAFAL, R. (2000). Deficits of task set in patients with left prefrontal cortex lesions. In S. Monsell \& J. Driver (Eds.), Control of cognitive processes: Attention and performance XVIII (pp. 627-651). Cambridge, MA: MIT Press.

Kellenbach, M. L., Brett, M., \& Patterson, K. (2003). Actions speak louder than functions: The importance of manipulability and action in tool representation. Journal of Cognitive Neuroscience, 15, 30-46.

Knowlton, B. J., Mangels, J. A., \& Squire, L. R. (1996). A neostriatal habit learning system in humans. Science, 273, 1399-1402.

Knowlton, B. J., Squire, L. R., \& GluCK, M. (1994). Probabilistic classification learning in amnesia. Learning \& Memory, 1, 106-120.

Koechlin, E., Basso, G., Pietrini, P., Panzer, S., \& Grafman, J. (1999). The role of the anterior prefrontal cortex in human cognition. Nature, 399, 148-151.

Konishi, S., NaKaJima, K., Uchida, I., Kikyo, H., Kameyama, M., \& Miyashita, Y. (1999). Common inhibitory mechanism in human inferior prefrontal cortex revealed by event-related functional MRI. Brain, 122, 981-991.

Kounios, J., Koenig, P., Glosser, G., DeVita, C., Dennis, K., Moore, P., \& Grossman, M. (2003). Category-specific medial temporal lobe activation and the consolidation of semantic memory: Evidence from fMRI. Brain Research: Cognitive Brain Research, 17, 484-494.

Lieberman, M. D., Chang, G. Y., ChiaO, J., Book Heimer, S. Y., \& KNowlton, B. J. (2004). An event-related fMRI study of artificial grammar learning in a balanced chunk strength design. Journal of Cognitive Neuroscience, 16, 427-438.

MacDonald, A. W., Cohen, J. D., Stenger, V. A., \& Carter, C. S. (2000). Dissociating the role of the dorsolateral prefrontal and anterior cingulate cortex in cognitive control. Science, 288, 1835-1838.

Martin, A., \& Chao, L. L. (2001). Semantic memory and the brain: Structure and processes. Current Opinion in Neurobiology, 11, 194201.

The Merriam-Webster dictionary. (1974). New York: Pocket Books.

Messinger, A., Squire, L. R., Zola, S. M., \& Albright, T. D. (2001). Neuronal representations of stimulus associations develop in the temporal lobe during learning. Proceedings of the National Academy of Sciences, 98, 12239-12244.

MILLER, E. K. (2000). The prefrontal cortex and cognitive control. $\mathrm{Na}$ ture Reviews Neuroscience, 1, 59-65.

Miller, E. K., \& CoHEN, J. D. (2001). An integrative theory of prefrontal cortex function. Annual Review of Neuroscience, 24, 167-202.

Milner, B. (1963). Effects of different brain lesions on card sorting. Archives of Neurology, 9, 90-100.

Miyashita, Y., \& HAYASHI, T. (2000). Neural representation of visual objects: Encoding and top-down activation. Current Opinion in Neurobiology, 10, 187-194.

Murray, E. A., Bussey, T. J., \& Wise, S. P. (2000). Role of prefrontal cortex in a network for arbitrary visuomotor mapping. Experimental Brain Research, 133, 114-129.

Nelson, J. K., Reuter-LorenZ, P. A., Sylvester, C. Y., Jonides, J., \& Sмiтh, E. E. (2003). Dissociable neural mechanisms underlying response-based and familiarity-based conflict in working memory. Proceedings of the National Academy of Sciences, 100, 11171-11175.

NoPPENEY, U., \& PRICE, C. J. (2003). Functional imaging of the semantic system: Retrieval of sensory-experienced and verbally learned knowledge. Brain \& Language, 84, 120-133.

OPITZ, B., \& FrIEDERICI, A. D. (2003). Interactions of the hippocampal system and the prefrontal cortex in learning language-like rules. NeuroImage, 19, 1730-1737. 
Packard, M. G., \& Knowlton, B. J. (2002). Learning and memory functions of the basal ganglia. Annual Review of Neuroscience, 25, 563-593.

PANDYA, D. N., \& Yeterian, E. H. (1998). Comparison of prefrontal architecture and connections. In A. C. Roberts, T. W. Robbins, \& L. Weiskrantz (Eds.), The prefrontal cortex: Executive and cognitive functions (pp. 51-66). Oxford: Oxford University Press.

PARKER, A., \& GAFFAN, D. (1998). Memory after frontal/temporal disconnection in monkeys: Conditional and nonconditional tasks, unilateral and bilateral frontal lesions. Neuropsychologia, 36, 259-271.

Passingham, R. E., \& Rowe, J. (2002). Dorsal prefrontal cortex: Maintenance in memory or attentional selection? In D. T. Stuss \& R. T. Knight (Eds.), Principles of frontal lobe function (pp. 221-232). Oxford: Oxford University Press.

Passingham, R. E., Toni, I., \& Rushworth, M. F. (2000). Specialisation within the prefrontal cortex: The ventral prefrontal cortex and associative learning. Experimental Brain Research, 133, 103-113.

Perani, D., Cappa, S. F., Bettinardi, V., Bressi, S., Gorno-Tempini, M., Matarrese, M., \& Fazio, F. (1995). Different neural systems for the recognition of animals and man-made tools. NeuroReport, 6, $1637-$ 1641.

Petrides, M. (1997). Visuo-motor conditional associative learning after frontal and temporal lesions in the human brain. Neuropsychologia, 35, 989-997.

PICARD, N., \& STRICK, P. L. (1996). Motor areas of the medial wall: A review of their location and functional activation. Cerebral Cortex, $\mathbf{6}$, 342-353.

PiCARd, N., \& STRICK, P. L. (2001). Imaging the premotor areas. Current Opinion in Neurobiology, 11, 663-672.

Pierrot-Deseilligny, C., Muri, R. M., Ploner, C. J., Gaymard, B., Demeret, S., \& Rivaud-Pechoux, S. (2003). Decisional role of the dorsolateral prefrontal cortex in ocular motor behaviour. Brain, 126, 1460-1473.

Poldrack, R. A., Clark, J., Pare-Blagoev, E. J., Shohamy, D., Creso Moyano, J., Myers, C., \& Gluck, M. A. (2001). Interactive memory systems in the human brain. Nature, 414, 546-550.

Poldrack, R. A., Wagner, A. D., Prull, M. W., Desmond, J. E., Glover, G. H., \& Gabrieli, J. D. (1999). Functional specialization for semantic and phonological processing in the left inferior prefrontal cortex. NeuroImage, 10, 15-35.

Pratesi, C. C., Valyear, K. F., Obhi, S. S., Brown, M. R., Marzi, C., \& Goodale, M. A. (2004). Neural correlates of preparatory set: Response selection versus movement planning (CD-ROM, Program No. 202.12, Abstracts viewer/itinerary planner). Washington, DC: Society for Neuroscience.

Quintana, J., \& Fuster, J. M. (1992). Mnemonic and predictive functions of cortical neurons in a memory task. NeuroReport, 3, 721-724.

Rainer, G., RaO, S. C., \& Miller, E. K. (1999). Prospective coding for objects in primate prefrontal cortex. Journal of Neuroscience, $\mathbf{1 9}$, 5493-5505.

RAMnANI, N., \& Owen, A. M. (2004). Anterior prefrontal cortex: Insights into function from anatomy and neuroimaging. Nature Reviews Neuroscience, 5, 184-194.

Ranganath, C., Johnson, M. K., \& D’Esposito, M. (2000). Left anterior prefrontal activation increases with demands to recall specific perceptual information. Journal of Neuroscience, 20, 1-5.

Ridderinkhof, K. R., van den Wildenberg, W. P., Segalowitz, S. J., \& CARTER, C. S. (2004). Neurocognitive mechanisms of cognitive control: The role of prefrontal cortex in action selection, response inhibition, performance monitoring, and reward-based learning. Brain \& Cognition, 56, 129-140.

Rowe, J. B., \& PAssingham, R. E. (2001). Working memory for location and time: Activity in prefrontal area 46 relates to selection rather than maintenance in memory. NeuroImage, 14, 77-86.

Rowe, J. B., Stephan, K. E., Friston, K., Frackowiak, R. S., \& PasSINGHAM, R. E. (2004). The prefrontal cortex shows context-specific changes in effective connectivity to motor or visual cortex during the selection of action or colour. Cerebral Cortex, 15, 85-95.

Rowe, J. B., Toni, I., Josephs, O., Frackowiak, R. S., \& Passingham, R. E. (2000). The prefrontal cortex: Response selection or maintenance within working memory? Science, 288, 1656-1660.
Rushworth, M. F., Ellison, A., \& WALsh, V. (2001). Complementary localization and lateralization of orienting and motor attention. $\mathrm{Na}$ ture Neuroscience, 4, 656-661.

Rushworth, M. F., Hadland, K. A., Paus, T., \& Sipila, P. K. (2002). Role of the human medial frontal cortex in task switching: A combined fMRI and TMS study. Journal of Neurophysiology, 87, 25772592.

SaKai, K., \& Passingham, R. E. (2003). Prefrontal interactions reflect future task operations. Nature Neuroscience, 6, 75-81.

Schumacher, E. H., \& D'Esposito, M. (2002). Neural implementation of response selection in humans as revealed by localized effects of stimulus-response compatibility on brain activation. Human Brain Mapping, 17, 193-201.

Schumacher, E. H., Elston, P. A., \& D'Esposito, M. (2003). Neural evidence for representation-specific response selection. Journal of Cognitive Neuroscience, 15, 1111-1121.

Seger, C. A., Poldrack, R. A., Prabhakaran, V., Zhao, M., Glover, G. H., \& GabrieLI, J. D. (2000). Hemispheric asymmetries and individual differences in visual concept learning as measured by functional MRI. Neuropsychologia, 38, 1316-1324.

Shallice, T., \& Burgess, P. W. (1991). Deficits in strategy application following frontal lobe damage in man. Brain, 114, 727-741.

Shohamy, D., Myers, C. E., Grossman, S., Sage, J., Gluck, M. A., \& POLDRACK, R. A. (2004). Cortico-striatal contributions to feedbackbased learning: Converging data from neuroimaging and neuropsychology. Brain, 127, 851-859.

Skosnik, P. D., Mirza, F., Gitelman, D. R., Parrish, T. B., Mesulam, M. M., \& RebeR, P. J. (2002). Neural correlates of artificial grammar learning. NeuroImage, 17, 1306-1314.

SMith, E. E., \& JonidES, J. (1999). Storage and executive processes in the frontal lobes. Science, 283, 1657-1661.

Snyder, L. H., Batista, A. P., \& Andersen, R. A. (2000). Intentionrelated activity in the posterior parietal cortex: A review. Vision Research, 40, 1433-1441.

Sohn, M. H., Ursu, S., Anderson, J. R., Stenger, V. A., \& Carter, C. S. (2000). Inaugural article: The role of prefrontal cortex and posterior parietal cortex in task switching. Proceedings of the National Academy of Sciences, 97, 13448-13453.

Strange, B. A., Henson, R. N., Friston, K. J., \& Dolan, R. J. (2001). Anterior prefrontal cortex mediates rule learning in humans. Cerebral Cortex, 11, 1040-1046.

Stuss, D. T., Levine, B., Alexander, M. P., Hong, J., Palumbo, C., Hamer, L., Murphy, K. J., \& IzuKawa, D. (2000). Wisconsin Card Sorting Test performance in patients with focal frontal and posterior brain damage: Effects of lesion location and test structure on separable cognitive processes. Neuropsychologia, 38, 388-402.

Sylvester, C. Y., \& Shimamura, A. P. (2002). Evidence for intact semantic representations in patients with frontal lobe lesions. Neuropsychology, 16, 197-207.

Sylvester, C. Y., Wager, T. D., Lacey, S. C., Hernandez, L., Nichols, T. E., Smith, E. E., \& Jonides, J. (2003). Switching attention and resolving interference: fMRI measures of executive functions. Neuropsychologia, 41, 357-370.

TaKeda, K., \& Funahashi, S. (2002). Prefrontal task-related activity representing visual cue location or saccade direction in spatial working memory tasks. Journal of Neurophysiology, 87, 567-588.

THOMPSON-SCHILL, S. L. (2003). Neuroimaging studies of semantic memory: Inferring "how" from "where." Neuropsychologia, 41, 280-292.

Thompson-Schill, S. L., D'Esposito, M., Aguirre, G. K., \& FArah, M. J. (1997). Role of the left inferior prefrontal cortex in retrieval of semantic knowledge: A reevaluation. Proceedings of the National Academy of Sciences, 94, 14792-14797.

Thompson-Schill, S. L., D’Esposito, M., \& KAN, I. P. (1999). Effects of repetition and competition on activity in left prefrontal cortex during word generation. Neuron, 23, 513-522.

Toni, I., Krams, M., Turner, R., \& Passingham, R. E. (1998). The time course of changes during motor sequence learning: A wholebrain fMRI study. NeuroImage, 8, 50-61.

Toni, I., \& Passingham, R. E. (1999). Prefrontal-basal ganglia pathways are involved in the learning of arbitrary visuomotor associations: A PET study. Experimental Brain Research, 127, 19-32. 
Toni, I., Ramnani, N., Josephs, O., Ashburner, J., \& Passingham, R. E. (2001). Learning arbitrary visuomotor associations: Temporal dynamic of brain activity. NeuroImage, 14, 1048-1057.

Toni, I., Rowe, J., Stephan, K. E., \& Passingham, R. E. (2002). Changes of cortico-striatal effective connectivity during visuomotor learning. Cerebral Cortex, 12, 1040-1047.

Toni, I., Schluter, N. D., Josephs, O., Friston, K., \& Passingham, R. E. (1999). Signal-, set- and movement-related activity in the human brain: An event-related fMRI study. Cerebral Cortex, 9, 35-49.

Tranel, D., Adolphs, R., Damasio, H., \& Damasio, A. R. (2001). A neural basis for the retrieval of words for actions. Cognitive Neuropsychology, 18, 655-670.

Tyler, L. K., STAMatakis, E. A., Dick, E., Bright, P., Fletcher, P., \& Moss, H. (2003). Objects and their actions: Evidence for a neurally distributed semantic system. NeuroImage, 18, 542-557.

Wagner, A. D., Bunge, S. A., \& BADre, D. (2004). Cognitive control, semantic memory, and priming: Contributions of prefrontal cortex. In M. S. Gazzaniga (Ed.), The new cognitive neurosciences (3rd ed., pp. 709-725). Cambridge, MA: MIT Press.

Wagner, A. D., Pare-Blagoev, E. J., Clark, J., \& Poldrack, R. A. (2001). Recovering meaning: Left prefrontal cortex guides controlled semantic retrieval. Neuron, 31, 329-338.

Wallis, J. D., Anderson, K. C., \& Miller, E. K. (2001). Single neurons in prefrontal cortex encode abstract rules. Nature, 411, 953-956.

WALlis, J. D., \& Miller, E. K. (2003). Neuronal activity in primate dorsolateral and orbital prefrontal cortex during performance of a reward preference task. European Journal of Neuroscience, 18, 2069-2081.
Wendelken, C., Donohue, S. E., Crone, E. A., \& Bunge, S. A. (2004). "BRAIN is to MIND as STOMACH is to ...?" Specifying the role of frontopolar cortex in analogical reasoning (CD-ROM, Program No. 548.21, Abstracts viewer/itinerary planner). Washington, DC: Society for Neuroscience.

White, I. M., \& WiSE, S. P. (1999). Rule-dependent neuronal activity in the prefrontal cortex. Experimental Brain Research, 126, 315-335.

Zelazo, P. D., Frye, D., \& Rapus, T. (1996). An age-related dissociation between knowing rules and using them. Cognitive Development, 11, 37-63.

ZELAZO, P. D., \& MüLLER, U. (2002). The balance beam in the balance: Reflections on rules, relational complexity, and developmental processes. Journal of Experimental Child Psychology, 81, 458-465.

\section{NOTES}

1. At a conference on prefrontal function (Rotman Research Institute, Toronto, March 2000), Joaquín Fuster vividly likened his and Patricia Goldman-Rakic's explorations in PFC to parachutists' landing in unknown territory and planting flags.

2. All the subjects were Americans with at least 4 years of experience driving in the United States and no experience driving abroad.

3. There is also substantial evidence that left anterior VLPFC selects between competing verbal representations (see, e.g., Jonides, Smith, Marshuetz, Koeppe, \& Reuter-Lorenz, 1998; Nelson, Reuter-Lorenz, Sylvester, Jonides, \& Smith, 2003; Thompson-Schill, D'Esposito, Aguirre, \& Farah, 1997; Thompson-Schill, D’Esposito, \& Kan, 1999).

(Manuscript received July 26, 2004;

revision accepted for publication November 8,2004 .) 